\section{Underwater endoscopic mucosal resection without submucosal lift}

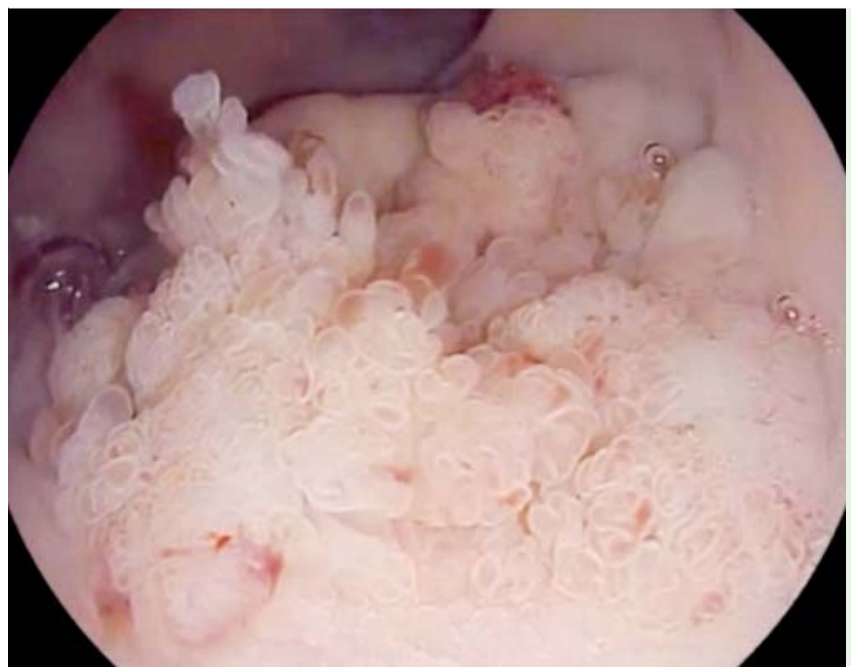

Fig. 1 Underwater view of a large (35-mm) rectal granular-type laterally spreading tumor that was removed using underwater endoscopic mucosal resection.

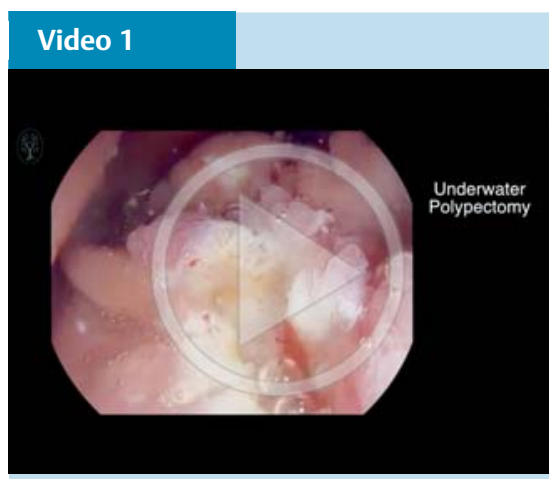

Piecemeal removal by underwater endoscopic mucosal resection of a $35-\mathrm{mm}$ granular lla laterally spreading tumor in the rectum, subsequently identified by pathology to be a tubulovillous adenoma.

Underwater polypectomy is a new technique that has been developed for the endoscopic resection of colonic lesions. Submucosal injection is not usually required using this method.

In this example of underwater polypectomy ( $\bullet$ Video 1 ), a 35-mm polyp (granulartype laterally spreading tumor; Kudo classification IIa and IV pit patterns) was identified in the upper rectum ( $\bullet$ Fig. 1 ). After the polyp had been detected, the colonic lumen was collapsed by aspiration of all air and was then completely filled with water. The margin of the polyp was identified using i-SCAN digital contrast in mode 1 (EPK-i7000 processor; Pentax Medical Europe, Hamburg, Germany). Underwater endoscopic mucosal resection (EMR) was performed using a $25-\mathrm{mm}$ snare (Snare
Master; Olympus, Tokyo, Japan) and endocut current, effect 3 , duration 1 , and interval 6 (VIO 200; Erbe Elektromedizin, Tuebingen, Germany).

The snare was positioned to resect a rim of normal tissue around the polyp margin. Polypectomy was completed in a piecemeal fashion. The resected pieces floated away from the polypectomy site and did not obscure the view; they were subsequently removed with a Roth net retrieval device (US Endoscopy, Mentor, Ohio, USA). During polypectomy we encountered an acute spurting bleed. Underwater, it was easy to identify the bleeding point as it made a blood trail upward. The patient's position was changed to expose the bleeding point, and bleeding was treated successfully using coagulation forceps (Olympus, Tokyo, Japan) with a coagulation current of $40 \mathrm{~W}$. The polypectomy was subsequently completed. Histology confirmed that the polyp was a tubulovillous adenoma.

Endoscopic mucosal resection (EMR) with submucosal injection using air or $\mathrm{CO}_{2}$ insufflation significantly distends the colonic lumen and thins the colonic wall during the procedure, which may increase the risk of complications. Submucosal injection both creates a potential risk of seeding neoplastic cells into deeper wall layers [1] and prolongs the procedure time. Endoscopic ultrasound studies of the water-filled colon have shown that the colonic wall retains its natural thickness [1]. The underwater immersion floating effect of the mucosa over the submucosa keeps it apart from the muscularis propria. This makes underwater EMR technically easier and safer to perform than traditional EMR. In addition, thermal injury to deeper layers is less likely under water immersion because of the cooling effect of the water. Patients tolerate the procedure better as the lumen is not distended and there is less distension-related pain.

In our experience, underwater EMR seems to be an effective, safe and well-tolerated procedure that can be performed by an endoscopist trained in traditional EMR. Diathermy marking of the polyp perimeter is not required, when the scope with i-SCAN is used, as the polyp margin is clearly identified [1]. This not only reduces the cost of the procedure but also reduces the procedure time. It can be an alternative to traditional EMR, which requires either air or $\mathrm{CO}_{2}$ insufflation.

Endoscopy_UCTN_Code_TTT_1AQ_2AD

\section{Competing interests: None}

\section{Sauid Ishaq ${ }^{1,2}$, Gian Eugenio Tontini ${ }^{3}$, Helmut Neumann ${ }^{4}$}

${ }^{1}$ Gastroenterology Department, Dudley Group Hospitals, Birmingham City University, Birmingham, United Kingdom

2 St. George's University, Grenada, West Indies

${ }^{3}$ Gastroenterology and Digestive Endoscopy Unit, IRCCS Policlinico San Donato, San Donato Milanese, Milan, Italy

${ }^{4}$ Medical Clinic, Interdisciplinary Endoscopy, University Medical Center Mainz, Mainz, Germany

\section{Reference}

1 Binmoeller KF. Underwater endoscopic mucosal resection. J Interv Gastroenterol 2014; 4: $113-116$

\section{Bibliography}

DOI http://dx.doi.org/

10.1055/s-0042-120263

Endoscopy 2016; 48: E371

(c) Georg Thieme Verlag KG

Stuttgart · New York

ISSN 0013-726X

Corresponding author

\section{Sauid Ishaq, FRCP}

Department of Gastroenterology

Birmingham City University

Dudley Group Hospitals

Dudley, DY1 2HQ

United Kingdom

Fax: +44-1384-244262

sauid.ishaq@dgh.nhs.uk 